\title{
Fabrication of mini-dialyzers using Anodic Aluminum Oxide and Polysulfone membrane and their comparative study for the improvement of hemodialysis to treat renal failure patients
}

\author{
Aleena Zahid ${ }^{1 *}$, Ajab Khan Kasi ${ }^{1}$, Jafar Khan Kasi ${ }^{1}$, Syed Muzamil \\ Bokhari ${ }^{1}$ and Humaira Abdul Wahid ${ }^{2}$ \\ 1. Department of Physics, University of Balochistan, Sariab Road Quetta-Pakistan \\ 2. Department of Botany University of Balochistan, Sariab Road Quetta-Pakistan \\ *Corresponding author's email: aleenazahid000@gmail.com \\ Citation \\ Aleena Zahid, Ajab Khan Kasi, Jafar Khan Kasi, Syed Muzamil Bokhari and Humaira Abdul Wahid. Fabrication of \\ mini-dialyzers using Anodic Aluminum Oxide and Polysulfone membrane and their comparative study for the \\ improvement of hemodialysis to treat renal failure patients. Pure and Applied Biology. Vol. 7, Issue 2, pp643-654. \\ http://dx.doi.org/10.19045/bspab.2018.70080
}

\begin{tabular}{llll}
\hline \hline Received: 04/03/2018 & Revised: 27/04/2018 & Accepted: 30/04/2018 & Online First: 12/05/2018 \\
\hline \hline
\end{tabular}

\section{Abstract}

Renal failure is one of the leading health issue in the world that effects people worldwide. Number of chronic renal failure patients are increasing day by day due to different factors. Hemodialysis is the most easily approachable treatment for renal failure patient. Efficiency of this treatment mainly depend upon semipermeable membrane used in hemodialyzer. Currently Synthetic polysulfone membrane is considered as a dialyzing membrane on commercial scale, which have irregular geometry such as pore size and pore shape responsible for the low toxin removal efficiency. A novel anodic aluminum oxide membrane (AAO) with highly ordered structure, perfect chemical stability and high thermal resistance is an attractive approach as dialyzing membrane. In this research commercially available polysulfone membrane and lab prepared highly ordered anodic aluminum oxide membrane were used to fabricated a mini dialyzer in lab to study different factors that effects the blood flow during the process of dialysis. Blood of 10 renal failure patients were used to conduct the process of dialysis in both mini dialyzers at lab scale. Toxin removal efficiency of both dialyzers were checked and compared with each other. Result showed that overall toxin removal efficiency of AAO base mini dialyzer was better than polysulfone membrane base mini dialyzer. However toxin removal efficiency for polysulfone base dialyzer remain same, while in AAO base dialyzer efficiency dropped with time. Results of this comparative study will be helpful to obtain a dialyzer that can provide maximum toxin removal efficiency to improve the process of dialysis to treat renal failure patients. Keywords: Anodic Aluminum oxide membrane (AAO); Blood; Dialyzer; Hemodialysis; Polysulfone membrane; Renal failure

\section{Introduction}

Renal failure is one of the comprehensive health burden and ranked $27^{\text {th }}$ on the base of mortality rate [1]. Kidneys are naturally made filters that filters out excessive water and toxins from the blood. They also have a vital responsibility of excretion, maintenance of metabolic processes and endocrine function 
related to different other organs [2]. Drop in kidney function up to $85-90 \%$ and Glomerular filtration rate (GFR) falls below 15 is called renal failure $[1,3]$. Renal failure may be acute (not enduring) or chronic (enduring). Hypertension, diabetes and ageing are the major cause of chronic renal failure, which gradually damages the kidney $[3,4]$. Nearly two million people globally receive renal failure treatment including renal transplant and dialysis [1, 5]. Renal transplant is the best treatment for end stage renal failure, but due to lack of donor availability, tissue and blood group matching this treatment is considered to be a far approach for many patients. So dialysis is an easy reachable approach for renal failure patients. It is an extracorporeal process of blood filtration to maintain kidney function through an artificial kidney called dialyzer [6]. Dialysis are of two types Peritoneal and Hemodialysis. In peritoneal dialysis, peritoneum a membrane in the abdomen of the patient is used to exchange substance between blood and dialysate (fluid containing essential electrolytes). Hemodialysis is considered to be a superior treatment as compare to peritoneal dialysis, because of high infection risk in patient abdomen after each peritoneal dialysis procedure [7]. Hemodialysis (HD) is used as renal replacement treatment in chronic and acute renal failure patient over the past five decades and first successful dialysis was reported in 1943 by Willem Kolff. [8, 9]. Major part of hemodialysis setup is semipermeable dialyzing membrane, where blood flows inside the membrane and dialysate flows around the porous membrane with negative pressure, which not only diffuse toxins from blood to dialysate, but also transfer essential electrolytes from dialysate to blood through the process of diffusion and ultrafiltration [10].

Semipermeable membrane majorly classified in to cellulose membrane (cuprophane, cupramnonium rayon), modified cellulose membrane (Cellulose acetate, Hemophane) and synthetic membranes (Polysulfone, Polyethersulfone) [11, 12]. Efficiency of dialysis procedure depend on the ability of membrane to eliminate toxin from the patient blood. While toxin removal capability of membrane depend on the membrane characteristics, such as orderliness and symmetry of pores, pore size, surface area, porosity, water permeability and biocompatibility [10]. Cellulose base membranes are considered to the firstly used semipermeable membrane for the process of hemodialysis $[7,13]$. Due to limited range of particle removal, non-biocompatible nature and low liquid permeability, these membrane are replace by synthetic polymers membranes. Synthetic semipermeable membrane have permeability 10 time to that of cellulose base membrane and also have wide range of particle removal [13]. Polysulfone membrane is one of the extensively used synthetic polymeric membrane used for the process of hemodialysis. It has non-uniformity in pore size and shape that cause albumin loss during HD treatment and cause blood and dialysate to flows in both compartment, which decreases the performance of HD treatment $[6,14]$. So both cellulose base and polymer synthetic membranes have a drawback of low toxin removal efficiency because of their irregular pore geometry and non-uniform pores distribution, which make them a nonideal material for the treatment of end stage renal disease. Beside these membranes another type of semipermeable membrane that is Anodic Aluminum oxide (AAO) membrane having uniform nanoporous structure was also used for hemodialysis. AAO membrane is a vigorously porous, electrically insulating and bio inert ceramic material, well-known for more than five decades [15]. Nano-porous AAO membrane have straight cylindrical aligned hexagonal 
porous structure with high thermal resistance, high porosity and high chemical resistance, which make it an excellent candidate for hemodialysis application [16]. Uniformly ordered porous structure of AAO is obtained using two step of anodization by controlling electrolyte, applied voltage and temperature. In 1995, Masuda et al. [17] firstly reported the formation of highly ordered AAO nanoporous structure using two step of anodization. Different approaches were made by researchers to improve AAO membrane and to use that membrane for hemodialysis procedure. Huang et al. [18] developed AAO membrane with uniform pore diameter of 10$50 \mathrm{~nm}$ by controlling parameters like voltage and electrolyte. Obtained membrane have high porosity, uniform pores and high temperature stability, which make this membrane suitable for hemodialysis applications. Attaluri et al. [6] made another attempt by developing AAO tubular membrane using two step of anodization. Efficiency of that membrane was then compared with polyethersulfone membrane. Developed tubular membrane have high thickness which make it not suitable for the filtration of blood and can't gave enough efficiency. So that membrane is not able to replace the kidney function for renal failure patient.

In present research an improved AAO nanoporous membrane having uniform porous structure was introduced for dialysis. Lab prepared AAO membrane and commercially available polysulfone were used to fabricate mini-dialyzers. Blood of ten renal failure patients were used to conduct the process of dialysis in mini-dialyzers at lab scale. The efficiency of AAO and polysulfone membranes were also compared.

\section{Materials and methods}

In this research two type of mini-dialyzers were fabricated. First by using commercially available polysulfone membrane and second by using fabricated AAO membrane.

\section{Fabrication of Polysulfone Membrane} Base Hemodialyzer

For the fabrication of polysulfone membrane base hemodialyzer, a glass base of $4 \mathrm{~mm}$ thickness was used. Glass base is $13.5 \mathrm{~cm}$ long and $2 \mathrm{~cm}$ wide as shown in Figure 1.

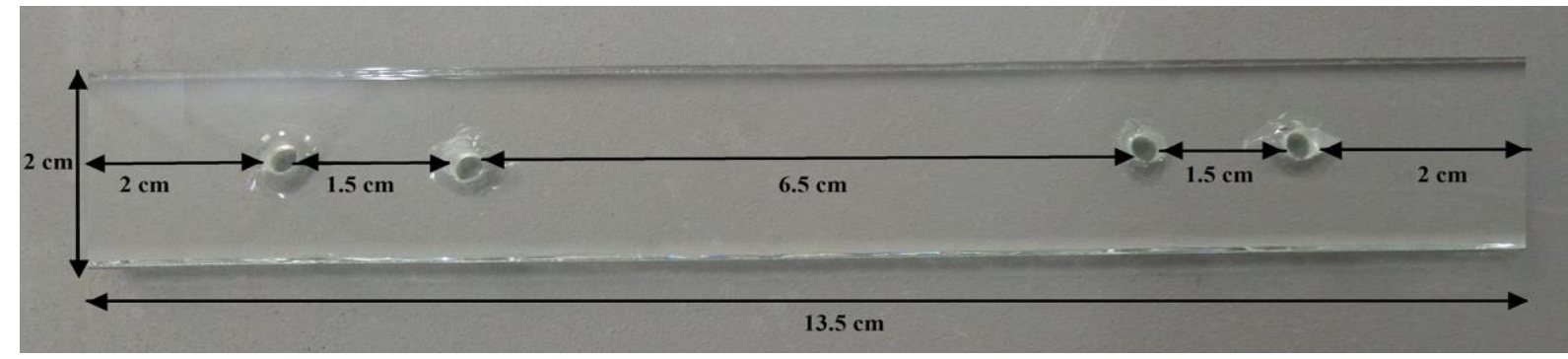

Figure 1. Dimensions of glass slab used to fabricate polysulfone membrane base hemodialyzer

For making inlet and out let in dialyzer, 4 holes were made in glass base using a driller as shown in (Figure 2b). After cleaning and proper drying, $1 \mathrm{~cm}$ long silicone tubes were inserted in all 4 holes as shown in Figure 2c. PDMS solution was applied to fix the silicone tubes in the holes. PDMS solution was obtained by combining curing agent and PDMS in a ratio of 1:10. After applying
PDMS, glass was annealed for $20 \mathrm{~min}$ at a temperature of $80^{\circ} \mathrm{C}$. Now a sticker of $6.5 \mathrm{~cm}$ was placed to seal hole and to make a channel on glass slab. After applying sticker, a thin layer of liquid silicone sealant of about $1 \mathrm{~mm}$ thickness was applied to cover the glass slab (Figure 2d, e). The sticker was removed and 9 polysulfone fiber was placed in the channel (Figure 2f, g). The glass slab was 
immediately covered with another glass slab of same dimension. The dialyzer was properly sealed by pressing and dried it for 42

hours (Figure 2h). The fabricated minidialyzer was used for experimental analysis.

(a)

(b)

(c)

(d)
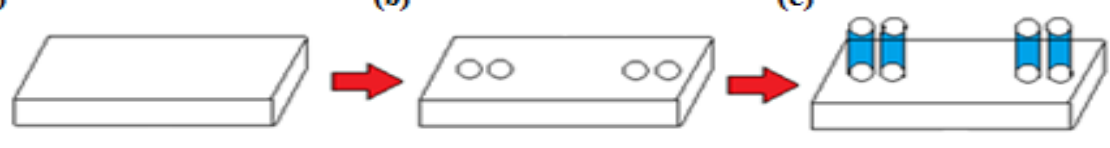

(g)

(f)

(e)

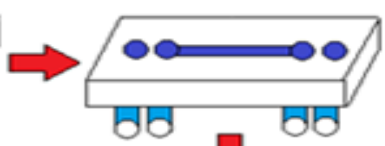

(h)
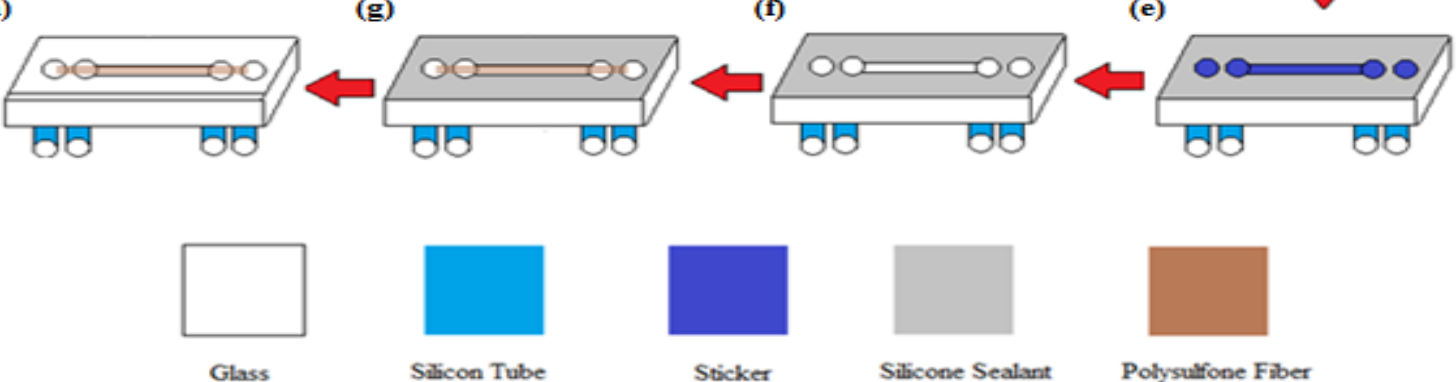

Figure 2. Schematic diagram of fabrication steps of polysulfone membrane base minidialyzer, (a) Glass substrate, (b) Drilling in glass substrate, (c) Silicone tubes attachment, (d) Sticker application on glass substrate, (e) Application of liquid silicone sealant layer, (f) Removing of sticker, (g) Placement of polysulfone fiber in the channel, (h) Sealing of glass substrate with plane glass

\section{Fabrication of AAO membrane base hemodialyzer}

For the AAO membrane base hemodialyzer, a highly ordered Anodic Aluminum oxide membrane was fabricated by two step anodization technique. For the fabrication of the membrane $99.99 \%$ pure $\mathrm{Al}$ sheet of $4 \times 1.5 \mathrm{~cm}$ dimension was used. Al substrate was ultrasonically degreased in acetone and D.I water for $10 \mathrm{~min}$. Al substrate was than electro chemically polished in a solution of per chloric acid and ethanol in ratio of 1:4 for 5 min at $0{ }^{\circ} \mathrm{C}$ to obtain a shiny and smooth surface. The substrate was again cleaned in D.I water and acetone. Two step anodization technique was used to obtained nano-porous AAO membrane. First step of anodization was performed in $0.5 \mathrm{~mol}$ sulphuric acid at $25 \mathrm{~V}$ for 2 hours at $0{ }^{\circ} \mathrm{C}$. Random nanoporous layer of $\mathrm{AAO}$ was developed on the top of $\mathrm{Al}$ substrate. For arranged hexagonal template on $\mathrm{Al}$ sheet, $\mathrm{AAO}$ was etched in solution of 6 wt $\%$ phosphoric acid and $1.8 \mathrm{wt} \%$ chromic acid for $30 \mathrm{~min}$ at $75{ }^{\circ} \mathrm{C}$. After etching, second step of anodization was performed under the same conditions for 3 hours to obtained AAO membrane on Al surface. For obtaining, free standing membrane chemical etching was not suitable because of it enhance the pore size during barrier layer etching. So Pulse detachment technique was used to overcome this problem. In this technique a voltage of $50 \mathrm{~V}$ was applied in electro-polishing solution for 3-4 seconds to obtained free standing membrane of uniform nanoporous structure.

After the fabrication of AAO membrane, this membrane was used in hemodialyzer set up. Figure 3 shows the fabrication steps of AAO membrane base mini-dialyser. For that a well prepared rectangular metallic holder was used. This set up is consist two glass pieces of dimension $4 \times 1.5 \mathrm{~cm}$, fixed between two metallic jackets. For the fabrication of AAO base mini-dialyzer, first step was to make inlets and outlets. For this purpose 4 holes 
were carefully made in glass substrate of metallic holder with the help of driller. After that $1 \mathrm{~cm}$ long silicone tubes were inserterd in all holes and PDMS was applied. To fixed the tubes in glass substrate, it was annealed at 80 ${ }^{\circ} \mathrm{C}$ for $20 \mathrm{~min}$. Stickers of $3 \times 1 \mathrm{~cm}$ dimension was placed at the center of glass pieces . After that a fine layer of silicone sealant of about $1 \mathrm{~mm}$ was applied on both glass pieces of methallic holder. Then sticker was carefully removed and silicone was dried for 42 hours. Channels on both of the glass pieces was observed. After proper drying free standing nanoporous AAO membrane with same dimension was cautiously transfered to one of the glass piece. Now this glass piece with free standing membrane was covered with other glass piece having channel. To avoid the leakage problem both glass pieces were pressed carefully .

These glass pieces that sandwicth the free standing membrane were placed between mettalic jacket and was sealed properly with the help of screws. This AAO membrane base mini dialyzer was then used to perform the process of hemodialysis.

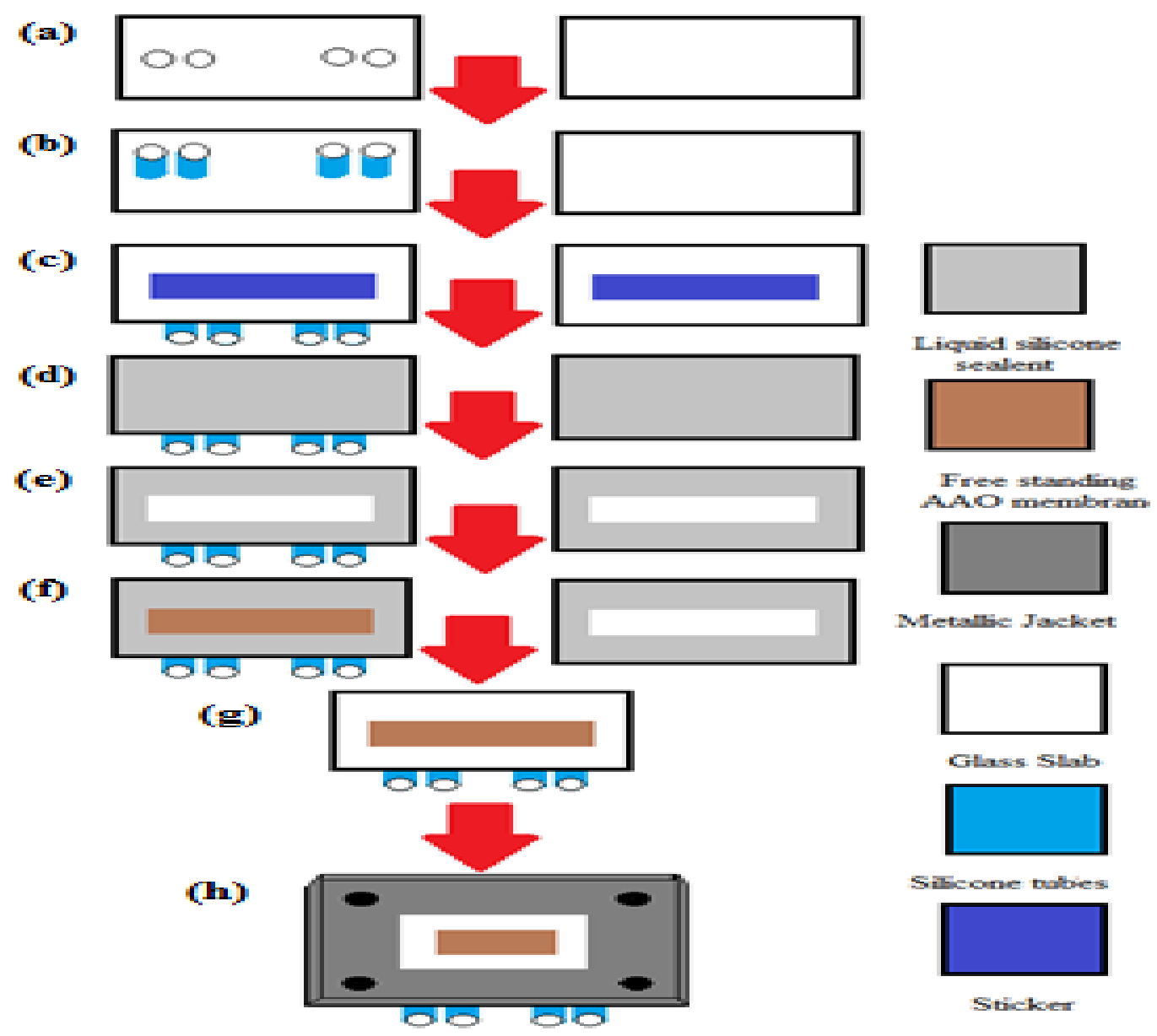

Figure 3. Schematic diagram of fabrication steps of AAO membrane base mini-dialyzer (a) Inlet and outlet holes on glass substrate, (b) $1 \mathrm{~cm}$ Silicone tubes sealed with PDMS, (c) Placement of $3 \times 1 \mathrm{~cm}$ dimension sticker, (d) Application of $1 \mathrm{~mm}$ thick layer of liquid silicone, (e) Sticker removal to obtain channel, (f) Placement of free standing AAO membrane within channel, (g) Fixation of glass piece, (h) Sealing of glass pieces in metallic holder 


\section{Results and discussion}

Cellulose base membranes are considered to be firstly used semipermeable membrane for the process of hemodialysis $[6,13]$. Because of its limited range of particle removal, nonbiocompatible nature and low liquid permeability, these membrane are replaced by synthetic polymer membranes. Synthetic semipermeable membranes have permeability 10 time to that of cellulose based membrane and also have wide range of particle removal [13]. Polysulfone membrane is one of the widely available synthetic polymeric membrane, because of its mechanical strength and controllable porous structure up to 0.04 microns [19]. In the present research, polysulfone membrane was considered as referenced membrane to check and compare the performance of AAO membrane for hemodialysis. Two sets of hemodialyzers were fabricated as explained in materials and methods. The hemodialysis was performed on both sets of dialyzers and their results were compared. The digital camera image of fabricated polysulfone membrane base mini-dialyzer is shown in (Figure 4). During the fabrication 6 polysulfone fibers with $200 \mu \mathrm{m}$ inner diameter and $45 \mu \mathrm{m}$ wall thickness were used. In the given image the outer tubes are inlet and outlet for blood and inner tubes are inlet and outlet for dialysate. Main reason to perform the dialysis using polysulfone membrane at lab scale was to study the even flow of blood throughout the fiber, which can't be observed in commercially available large size dialyzers.

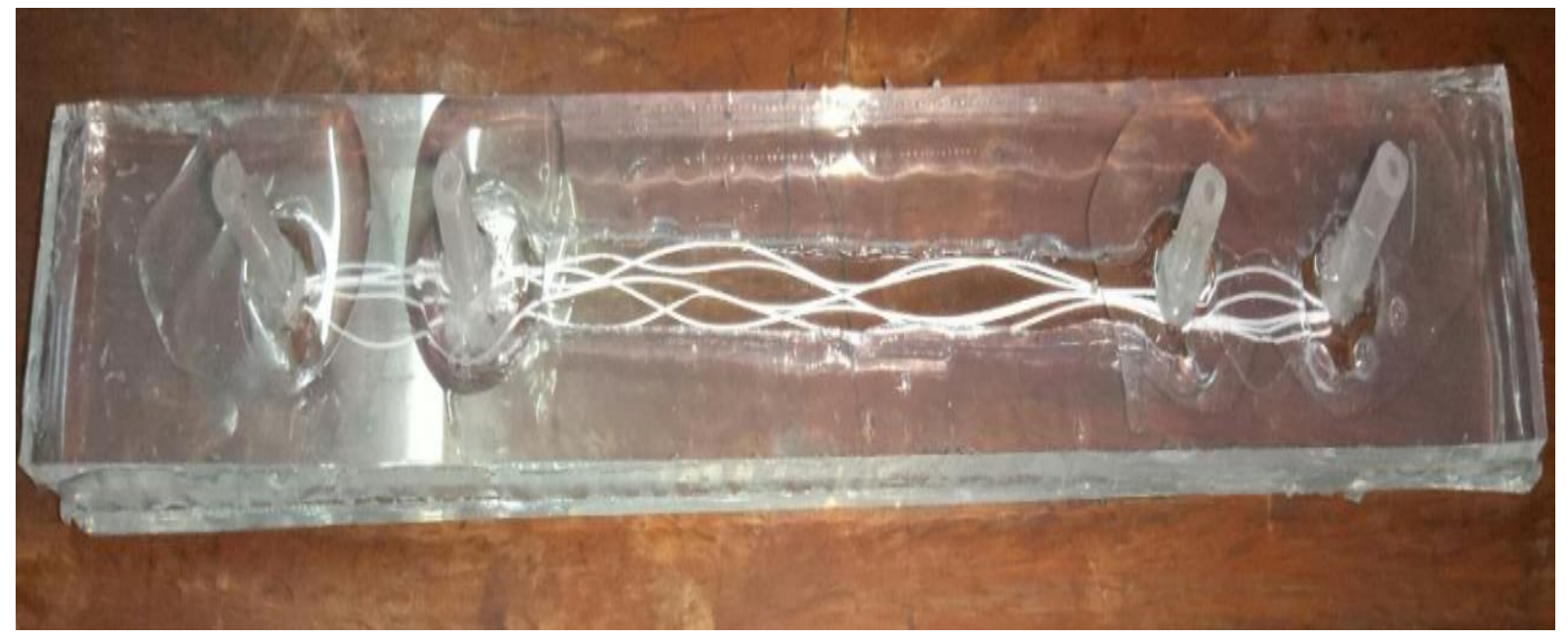

Figure 4. Mini-dialyzer using UF 5.5 polysulfone dialyzing membrane

SEM analysis of polysulfone membrane shown in Figure 5 displays the unique spongy outer layer and highly dense nanopores inner layer. Inner dense structure shown in (Figure 5e \& f) is mainly responsible for blood filtration in hemodialysis process. To observe the structure of single polysulfone fiber, the fiber was fixed in liquid silicone sealant. After proper drying, fiber within the silicone was cut with sharp cutter to obtain its cross- sectional view. Due to unique highly dense porous structure these membranes are used for different applications like gas separation, fluid filtration, food processing and hemodialysis process [18]. Because of very high flow rate at very minimal pressure difference and highly porous structure, this polysulfone membrane act as a promising commercially available membrane for hemodialysis. 


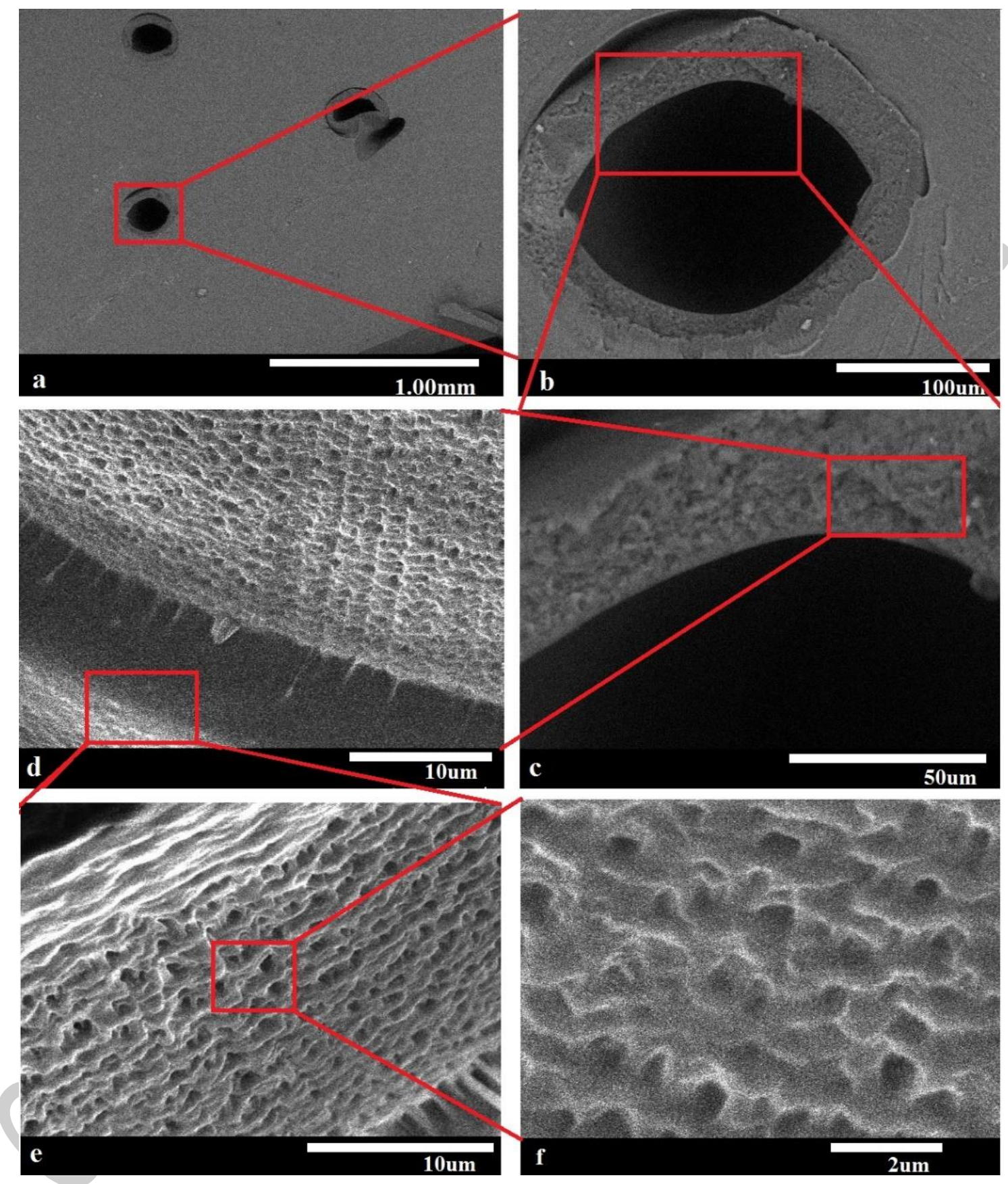

Figure 5. SEM images of UF 5.5 polysulfone dialyzing membrane (a) Cross-sectional view of membrane (b,c,d,e,f) High magnification images showing the detailed structure of polysulfone membrane

Second step of the current research was the fabrication of highly ordered lab prepared AAO membrane base mini-dialyzer as shown in (Figure 6), for the comparative study with polysulfone membrane base mini-dialyzer. 


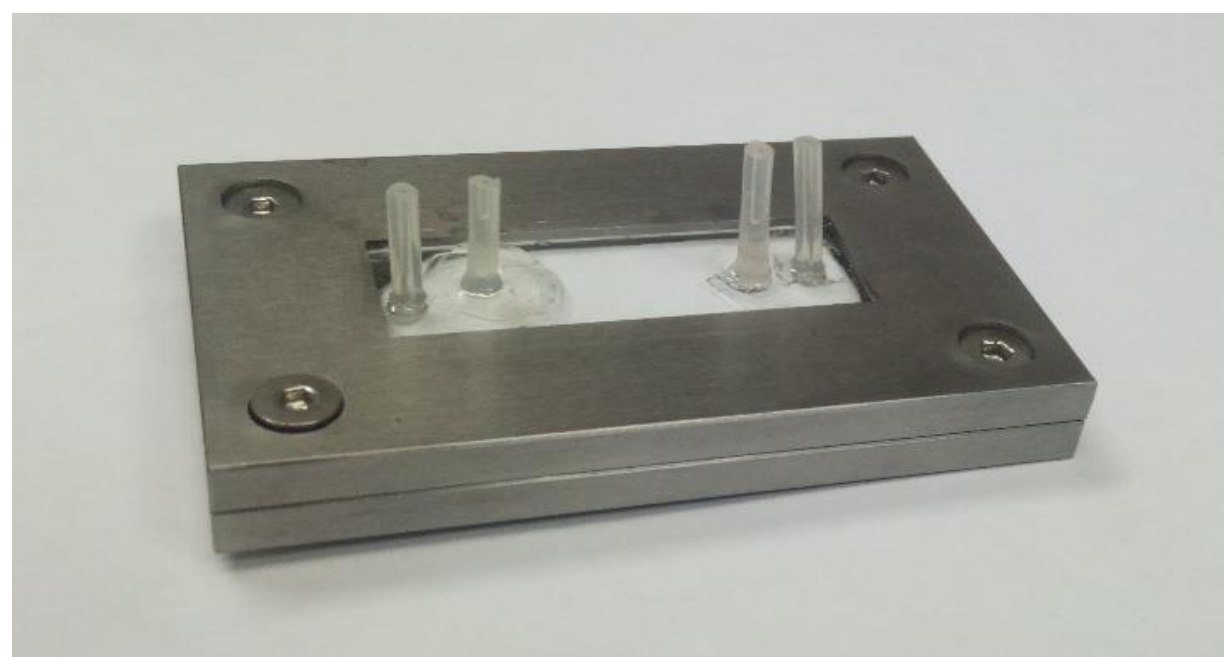

Figure 6. Digital camera image of AAO membrane base hemodialyzer

For the evaluation of fabricated $\mathrm{AAO}$ membrane used in the mini-dialyzer shown in Figure 6, Scanning Electron Microscope was used. Figure 7 shows the SEM analysis of lab prepared AAO membrane have a pore diameter of about $20 \mathrm{~nm}$ and thickness of about $5 \mu \mathrm{m}$. Obtained AAO membrane have uniform hexagonal nanoporous structure. Figure 7a \& b shows uniformly ordered upper and lower surface while Figure 7c shows the cross sectional view of aligned pores of nanoporous AAO membrane.
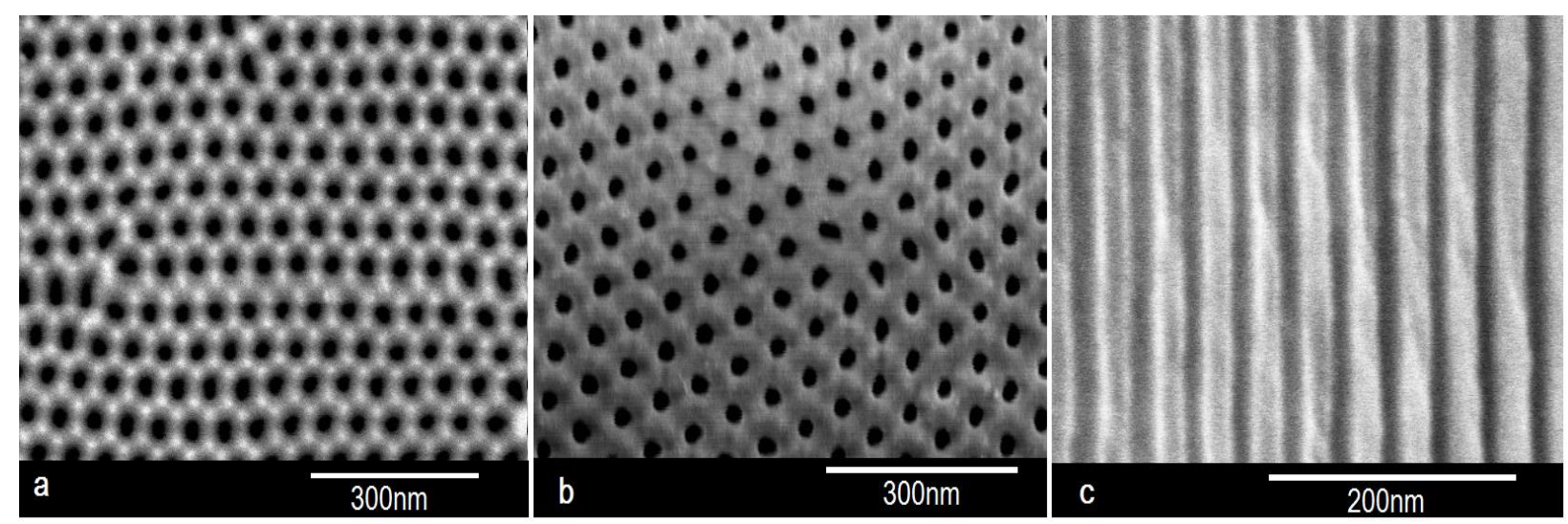

Figure 7. (a, b) SEM image of upper and lower surface view of AAO membrane, (c) SEM image of cross sectional view of AAO membrane

As explain in experimental section to perform the process of hemodialysis using both of the mini-dialyzers, blood of renal failure patients were used. Total 10 blood sample of 7 male and 3 female patients with different blood urea and creatinine level were collected. Basic data of the patient such as patient age, sex and blood group was obtained and recorded. Process of dialysis was performed on each blood sample using both of the mini-dialyzers. In mini-dialyzers out of four, one set of inlet and outlet was used for blood flow, while other set of inlet and outlet was used for the flow of dialysate. Dialysate was used to maintain electrolyte that is lost during the dialysis procedure. Dialysate is a combination of water mixed with acidic part and basic part. For making 
dialysate Deionized water was used, which was almost $90 \%$ pure of deionized ions. Basic composition of concentrated acidic part of dialysate $(\mathrm{g} / \mathrm{l})$ is $\mathrm{NaCl}=210.69, \mathrm{KCl}=$ 5.22, $\mathrm{CH}_{3} \mathrm{COOH}=6.31, \mathrm{CaCl}_{2}=6.43$, $\mathrm{MgCl}_{2}=3.56, \quad \mathrm{C}_{6} \mathrm{H}_{14} \mathrm{O}_{7}=38.5$ and composition of base part of dialysate $(\mathrm{mmol} / \mathrm{l})$ is sodium $=1002$, bicarbonate $=$ 1002. To prepare 2.60 liter of dialysate 2 liter of acidic part was mixed with $60 \mathrm{ml}$ of base part. $\mathrm{pH}$ of the dialysate which effect the hemodialysis efficiency in the patient body was between 6.5 to 7.5. High temperature can cause hemolysis and low temperature can cause shivering in the patient body [20], so for the process of hemodialysis the temperature was maintained between $350{ }^{\circ} \mathrm{C}$ to $360{ }^{\circ} \mathrm{C}$. Digital camera image of dialyzing setup can be seen in (Figure 8), which is consist of two peristaltic pump, dialysate source beaker and dialysate drain beaker. Flow of blood and dialysate in mini-dialyzers was controlled by using two way peristaltic pump which applies negative pressure. For the purification of blood, toxin material was diffused from blood to dialysate and essential components were transferred from dialysate to blood across the dialyzing membrane during the process of hemodialysis.

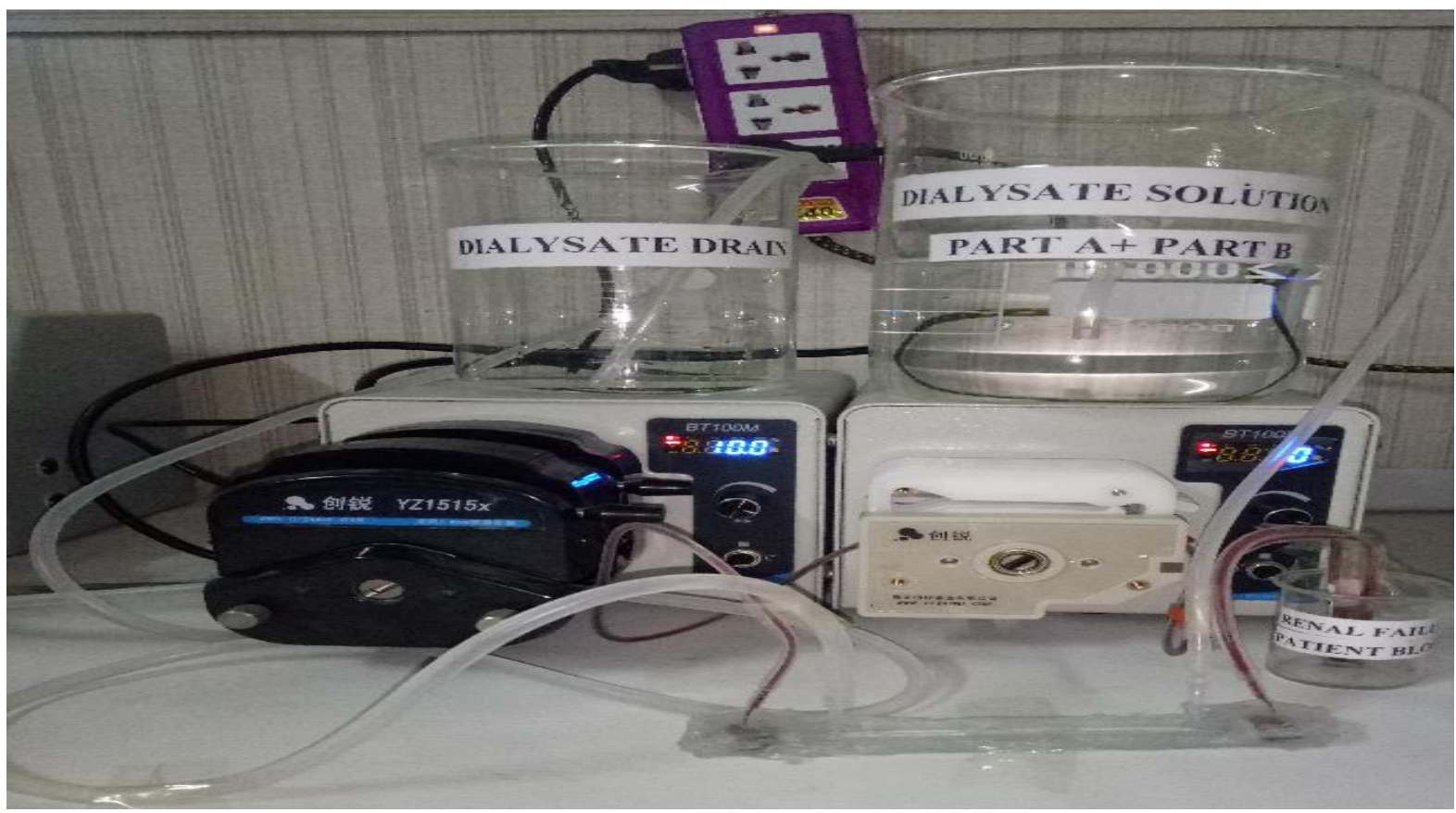

Figure 8. Digital camera image of hemodialyzing setup

Dialysis process was performed on each blood sample for 3 hours using both minidialyzers. In single pass, dialysate flows at a rate of $5.5 \mathrm{ml} / \mathrm{min}$. To conduct the hemodialysis steady and safely without being any irruption due to clotting effect, infusion of anticoagulant into patient is mandatory [19]. So Heparin was used as anticoagulant and added in the blood before passing the blood through the dialyzer. An average blood flow rate of $2-2.5 \mathrm{ml} / \mathrm{min}$ was maintained during the procedure.

Two main features of hemodialysis procedure is the removal of urea and creatinine, which are accumulated in the body, when kidneys are not working properly. Blood samples used for the dialysis process have high urea and creatinine level. After the dialysis procedure on each blood sample, toxins such as urea and creatinine 
were reduced. (Table 1) shows the pre and post urea level and urea reduction ratio for each sample and (Table 2) shows pre and post creatinine level and creatinine removal ratio for each sample. From these results, it is clear that urea reduction ratio and creatinine removal ratio of AAO membrane is greater than polysulfone membrane base dialyzer. Previous research also showed that ultrafiltration rate per unit area of the membrane that is termed as ultrafiltration flux is roughly proportional to fourth power of mean pore radius of the membrane. Thus by making small variation in the pore size water permeability increase largely [21]. So AAO membrane with uniformly ordered pores have better efficiency as compare to unordered porous polysulfone membrane.

Table 1. Pre and post urea level and urea reduction ratio

\begin{tabular}{|c|c|c|c|c|c|c|}
\hline \multirow{2}{*}{ S. No. } & \multirow{2}{*}{ Samples } & \multirow{2}{*}{$\begin{array}{c}\text { Pre } \\
\text { dialysis } \\
\text { Urea } \\
\text { Level } \\
\text { (mg/dl) }\end{array}$} & \multicolumn{2}{|c|}{$\begin{array}{c}\text { Post dialysis Urea Level } \\
\text { (mg/dl) }\end{array}$} & \multicolumn{2}{|c|}{ Urea Reduction Ratio } \\
\hline & & & $\begin{array}{c}\text { PSF } \\
\text { dialyzer }\end{array}$ & AAO dialyzer & $\begin{array}{c}\text { PSF } \\
\text { dialyzer }\end{array}$ & AAO dialyzer \\
\hline 1. & $\mathbf{A}$ & 296 & 52 & 45 & $82 \%$ & $86 \%$ \\
\hline 2. & B & 290 & 54 & 45 & $81 \%$ & $84 \%$ \\
\hline 3. & $\mathbf{C}$ & 193 & 45 & 35 & $77 \%$ & $82 \%$ \\
\hline 4. & D & 213 & 51 & 47 & $76 \%$ & $78 \%$ \\
\hline 5. & $\mathbf{E}$ & 206 & 51 & 46 & $75 \%$ & $77 \%$ \\
\hline 6. & $\mathbf{F}$ & 199 & 49 & 47 & $75 \%$ & $76 \%$ \\
\hline 7. & $\mathbf{G}$ & 180 & 49 & 47 & $72 \%$ & $74 \%$ \\
\hline 8. & $\mathbf{H}$ & 122 & 36 & 34 & $70 \%$ & $72 \%$ \\
\hline 9. & $\mathbf{I}$ & 135 & 42 & 39 & $68 \%$ & $71 \%$ \\
\hline 10. & $\mathbf{J}$ & 144 & 49 & 46 & $66 \%$ & $68 \%$ \\
\hline
\end{tabular}

Table 2. Pre and post creatinine level and creatinine clearance ratio

\begin{tabular}{|c|c|c|c|c|c|c|}
\hline \multirow{2}{*}{ S. No. } & \multirow{2}{*}{ Samples } & \multirow{2}{*}{$\begin{array}{c}\text { Pre dialysis } \\
\text { Creatinine } \\
\text { Level } \\
(\mathrm{mg} / \mathrm{dl})\end{array}$} & \multicolumn{2}{|c|}{$\begin{array}{c}\text { Post dialysis Urea Level } \\
\text { (mg/dl) }\end{array}$} & \multicolumn{2}{|c|}{ Creatinine removal Ratio } \\
\hline & & & $\begin{array}{c}\text { PSF } \\
\text { dialyzer }\end{array}$ & $\begin{array}{c}\text { AAO } \\
\text { dialyzer }\end{array}$ & $\begin{array}{c}\text { PSF } \\
\text { dialyzer }\end{array}$ & AAO dialyzer \\
\hline 1. & $\mathbf{A}$ & 8 & 2.8 & 2.2 & $65 \%$ & $73 \%$ \\
\hline 2. & B & 7.7 & 2.8 & 2.3 & $64 \%$ & $70 \%$ \\
\hline 3. & $\mathbf{C}$ & 7.1 & 2.7 & 2.2 & $62 \%$ & $69 \%$ \\
\hline 4. & D & 6.8 & 2.5 & 2.2 & $63 \%$ & $68 \%$ \\
\hline 5. & $\mathbf{E}$ & 6.6 & 2.6 & 2.3 & $61 \%$ & $65 \%$ \\
\hline 6. & $\mathbf{F}$ & 13.5 & 5.4 & 5.1 & $60 \%$ & $62 \%$ \\
\hline 7. & $\mathbf{G}$ & 7.2 & 3.0 & 2.8 & $58 \%$ & $61 \%$ \\
\hline 8. & $\mathbf{H}$ & 6.2 & 2.7 & 2.5 & $56 \%$ & $60 \%$ \\
\hline 9. & I & 6.0 & 2.9 & 2.6 & $52 \%$ & $57 \%$ \\
\hline 10. & $\mathbf{J}$ & 5.9 & 3.5 & 3.1 & $41 \%$ & $47 \%$ \\
\hline
\end{tabular}


Reusing of different medical devices, such as hemodialyzer are considered to be a new trend to make device more cost effective. In different countries about $83 \%$ of end stage renal failure patient are treated with reprocessed dialyzer [22]. Reprocessing of dialyzer effects the dialyzing performance if it was not used properly such that the minor residuals of blood start depositing in the blood chamber and dialyzing membrane. Deposition of blood in the blood chamber of dialyzer is one of the main cause of infection in the patient and deposition of the blood in the pores of dialyzing membrane cause the blockage of pores. Both these factors decreases the efficiency of dialysis treatment. So another attempt was made in present research by using the same dialyzers twice for same blood sample. Results of that attempt shows that blood filtration rate of the AAO membrane drop with the time and clotting effect was observed even in the presence of anti-coagulant Heparin. This is mainly due to the blockage in the membrane with small blood residuals. On other hand clotting effect in polysulfone membrane was lesser as compare to AAO and blood filtration rate of polysulfone dialyzer almost remain same during the whole procedure. Where some past studies shows that polysulfone base dialyzer can be reuse after sterilizing using bleach or formaldehyde and a loss of $17 \mathrm{~g}$ of protein was observed after 20 to 25 reuses [23]. So present results shows that AAO membrane is not suitable for the reusing even after sterilizing, while polysulfone is a suitable option for the dialysis as reprocessed dialyzer.

\section{Conclusion}

Present study showed that AAO membrane has highly ordered porous structure having aligned pores that distributes evenly. Results showed that toxin removal efficiency of AAO membrane is better than polysulfone membrane, which make it a good candidate for hemodialysis procedure. But for long term use AAO membrane's efficiency drop with time due to blockage of membrane pores.

\section{Authors' contributions}

Conceived and designed the experiments: A Zahid \& AK Kasi, Performed the experiments: A Zahid, Analyzed the data: AK Kasi \& A Zahid, Contributed materials/ analysis/ tools: JK Kasi \& SM Bokhari, Wrote the paper: A Zahid, AK Kasi \& HA Wahid.

\section{Acknowledgements}

The author is very obliged to Fayyaz Blood Testing Lab, Quetta and Dr Ejaz from Kidney Center, Quetta, Balochistan, Pakistan for providing Patients Blood Samples. Author is also grateful to University of Karachi, Pakistan for the SEM Analysis.

\section{References}

1. Jha V, Garcia-Garcia G, Iseki K, Li Z, Naicker S, Plattner B \& Yang CW (2013). Chronic kidney disease: global dimension and perspectives. Lancet 382(9888): 260-272.

2. Eckardt KU, Coresh J, Devuyst O, Johnson RJ, Köttgen A, Levey AS \& Levin A (2013). Evolving importance of kidney disease: from subspecialty to global health burden. Lancet 382(9887): 158-169.

3. Alebiosu CO \& Ayodele OE (2005). The global burden of chronic kidney disease and the way forward. Ethnicity and Disease 15(3): 418.

4. Kurokawa K, Nangaku M, Saito A, Inagi R \& Miyata T (2002). Current issues and future perspectives of chronic renal failure. J Ame Sci of Nephro 13(1): S3S6.

5. Ashraf MW, Qureshi MZ, Ghaffar F, Tayyaba S \& Afzulpurkar N (2016). Structural study of AAO membrane during the dialysis process. ICISE: 226231.

6. Attaluri AC, Huang Z, Belwalkar A, Van Geertruyden W, Gao D \& Misiolek W 
(2009). Evaluation of nano-porous alumina membranes for hemodialysis application. ASAIO. J 55(3): 217-223.

7. Kee CM \& Idris A (2010). Permeability performance of different molecular weight cellulose acetate hemodialysis membrane. Separation and Purification Technol 75(2): 102-113.

8. Kolff WJ, Berk HT, Welle NM, Ley, AJW, Dijk EC \& Noordwijk J (1944). The artificial kidney: a dialyser with a great area. J of Inter Medi 117(2): 121134.

9. Clark WR, Hamburger RJ \& Lysaght MJ (1999). Effect of membrane composition and structure on solute removal and biocompatibility in hemodialysis. Kidney internat 56(6): 2005-2015.

10. Clark WR \& Ronco C (2001). Determinants of haemodialyser performance and the potential effect on clinical outcome. Nephrology Dialysis Transplantation 16(5): 56-60.

11. Hakim RM, Held PJ, Stannard DC, Wolfe RA, Port FK, Daugirdas JT \& Agodoa L (1996). Effect of the dialysis membrane on mortality of chronic hemodialysis patients. Kidney Internat 50(2): 566-570.

12. La Flamme KE, Popat KC, Leoni L, Markiewicz E, La Tempa TJ, Roman BB \& Desai T A (2007). Biocompatibility of nanoporous alumina membranes for immunoisolation. Biomaterials 28(16): 2638-2645.

13. Gao A, Liu F \& Xue L (2014). Preparation and evaluation of heparinimmobilized poly (lactic acid)(PLA) membrane for hemodialysis. $J$ Membr Sci 452: 390-399.

14. Huang Z, Zhang W, Yu J \& Gao D (2007). Nanoporous alumina membranes for enhancing hemodialysis. $J$ Medi Devi 1(1): 79-83.
15. Poinern GE, Ali N \& Fawcett D (2011). Progress in nano-engineered anodic aluminum oxide membrane development. Materi 4(3): 487-526.

16. Velleman L, Triani G, Evans PJ, Shapter JG \& Losic D (2009). Structural and chemical modification of porous alumina membranes. Micropo and Mesopos Materi 126(1): 87-94.

17. Masuda H \& Fukuda K (1995). Ordered metal nanohole arrays made by a twostep replication of honeycomb structures of anodic alumina. Sci 268(5216): 1466.

18. Huang Z, Zhang W, Yu J \& Gao D (2007). Nanoporous alumina membranes for enhancing hemodialysis. $J$ Medi Devi 1(1): 79-83.

19. Hasegawa $T$, Iwasaki $Y$ \& Ishihara $K$ (2001). Preparation and performance of protein-adsorption-resistant asymmetric porous membrane composed of polysulfone/phospholipid polymer blend. Biomate 22(3): 243-251.

20. Selby NM \& McIntyre CW (2006). A systematic review of the clinical effects of reducing dialysate fluid temperature. Nephro Dial Transplant 21(7): 18831898.

21. Clark WR, Hamburger RJ \& Lysaght MJ (1999). Effect of membrane composition and structure on solute removal and biocompatibility in hemodialysis. Kid internat 56(6): 2005-2015.

22. Post JB (2010). Thrombocytopenia associated with use of a biocompatible hemodialysis membrane: a case report. Ameri J Kid Dis 55(6): e25-e28.

23. Ahrenholz PG, Winkler RE, Michelsen A, Lang DA \& Bowry SK (2004). Dialysis membrane-dependent removal of middle molecules during hemodiafiltration: the beta 2microglobulin/albumin relationship. Clini Nephro 62: 21-28. 